\title{
Assay for neurite outgrowth quantification
}

Marithea Smit, Jay Leng, and Richard L. Klemke

Innovative Cell Systems LLC, Temecula, CA, USA

BioTechniques 35:254-256 (August 2003)

Proper neuronal migration and establishment of circuitry are key processes for nervous system functioning. During development, neurons extend numerous processes that differentiate into dendrites and axons. These processes, also termed neurites, are critical for communication between neurons.

The characterization of neurite formation, maturation, and collapse/resorption is an area of intense interest because these cellular processes are essential for the interconnection of neuronal cell bodies. Neurites are particularly interesting in relation to neuropathological disorders, neuronal injury/regeneration, and neuropharmacologic research and screening. Nerve transection was once believed to be irreversible, but it has recently become apparent that the inability of damaged nerve fibers to regenerate is an active process under the control of molecules able to inhibit and repulse growing neurites (1-4). Therefore, major efforts in central nervous system drug discovery research are focused on the identification of compounds that affect the growth of neurites. However, the study of neurites is greatly hampered by the difficulty of isolating and quantifying these minute organelles. Currently available methods for measuring neurite outgrowth consist of the manual examination of individual cells under a microscope or the measurement of total fluorescence from a labeled neuronal cell population using a fluorescence plate reader $(5,6)$. The caveats of these methods are that the former is labor-intensive and subjective and the latter cannot discriminate between fluorescently labeled neuronal cell bodies and neurites. Consequently, the lack of a means to isolate and purify sufficient neurite material and the lack of a uniform and highly reproducible method of neurite quantification have impeded an understanding of the role of these organelles in develop- ment, injury, and disease states.

Using an extension of the traditional Boyden Chamber technology (7), we developed an assay that is quick and efficient for the quantification of neurite outgrowth in a 24-well format. This method is based on the use of a transwell cell culture insert (chamber), containing a permeable, polycarbonate membrane with $3-\mu \mathrm{m}$ pores at its base. The inserts are designed to fit into a receiver vessel, which in use contains a solution intended to contact the bottom of the membrane. These permeable membranes should allow for the discrimination between neurites and cell bodies, since neurites have cross sections of less than $0.8 \mu \mathrm{m}$ while cell bodies average approximately $20 \mu \mathrm{m}$. Therefore, by inducing neurites to traverse these membrane pores, a purified population of neurites would appear on the underside of the membrane, distal to the surface on which neural cell bodies are deposited.

Neurites are very delicate organelles and require attachment to membranes for both signaling and recovery, which involve the detection of macromolecular signals by the growth cone, a complex sensing apparatus that caps the neurite extension $(8,9)$. Therefore, the bottom of the membrane must be treated with extracellular matrix (ECM) proteins to permit neurites emerging from the cell to traverse the membrane pores, sprout, track, and attach to the underside of the membrane.

For the development of this assay, two different cell lines, mouse neuroblastoma N1E-115 and rat PC12 cells (both from ATCC, Manassas, VA, USA), were used to illustrate the application of our assay in different cell lines. N1E-115 cells were cultured in Dulbecco's modified Eagle's medium (DMEM) containing 10\% fetal bovine serum (FBS) (both from HyClone, Lo- gan, UT, USA). PC12 cells were cultured in RPMI-1640 (HyClone) containing 10\% FBS. Both cell lines were kept at $37^{\circ} \mathrm{C}$ in $5 \% \mathrm{CO}_{2}$. Each of these cell lines was split and maintained in culture media until 70\%-80\% confluent. Upon reaching the desired confluence, cells were exposed to external stimuli to induce differentiation and neurite extension. Specifically, the murine neuroblastoma cells were cultured overnight in N1E-115 differentiation media [serum-free conditioning media containing $0.1 \%$ bovine serum albumin (BSA)], and the rat cells were cultured for two days in PC12 differentiation media [serum-free conditioning media containing $100 \mathrm{ng} / \mathrm{mL}$ nerve growth factor (Alomone Laboratories, Jerusalem, Israel)].

Costar ${ }^{\circledR}$ Transwell cell culture inserts (Corning Life Sciences, Corning, NY, USA) were prepared for neurite outgrowth. Since each cell line has different ECM protein requirements for attachment and propagation, we used laminin/ phosphate-buffered saline (PBS) (10 $\mu \mathrm{g} / \mathrm{mL}$ ) (Sigma-Aldrich, St. Louis, MO, USA) for N1E-115 $(10,11)$ and collagen I/PBS $(10 \mu \mathrm{g} / \mathrm{mL})$ (Chemicon International, Temecula, CA, USA) for PC12 cells (12). Undersides of membranes were coated by aliquoting $500 \mu \mathrm{L}$ of the appropriate ECM protein solution into a well of a 24-well plate and placing an unused insert into the well (Figure 1). While the membranes were incubating for $2 \mathrm{~h}$ at $37^{\circ} \mathrm{C}$ to allow for coating by the ECM solution, N1E-115 and PC12 cells were removed from culture dishes with trypsin-free detachment buffer (Invitrogen, Carlsbad, CA, USA), and a cell viability count was performed with trypan blue (Sigma-Aldrich). Cell lines were then resuspended in their respective differentiation media, as mentioned above, at $1 \times 10^{6}$ cells $/ \mathrm{mL}$. Subsequently, the membranes were removed from laminin and/or collagen I (no rinse required) and placed into a well of a 24-well dish containing $500 \mu \mathrm{L}$ differentiation media (Figure 1). A cell suspension volume of $100 \mu \mathrm{L}$ (containing $1-2 \times 10^{5}$ cells) was added into the insert chamber on top of the membrane. Cells were allowed to extend neurites through the membrane pores to the lower chamber (underside of membrane) for $4-24 \mathrm{~h}$ at $37^{\circ} \mathrm{C}$ (Figure 1). 
Following the neurite extension period, inserts were removed from wells, and membranes (containing neurites) were gently rinsed in excess PBS and fixed in $100 \%$ ice-cold methanol for 20 min at room temperature. Membranes were removed from fixative and gently rinsed in excess PBS, and the neurites were stained with a crystal violet solution $(0.09 \%$ crystal violet; $7 \%$ reagent alcohol) (Sigma-Aldrich). Stained neu-

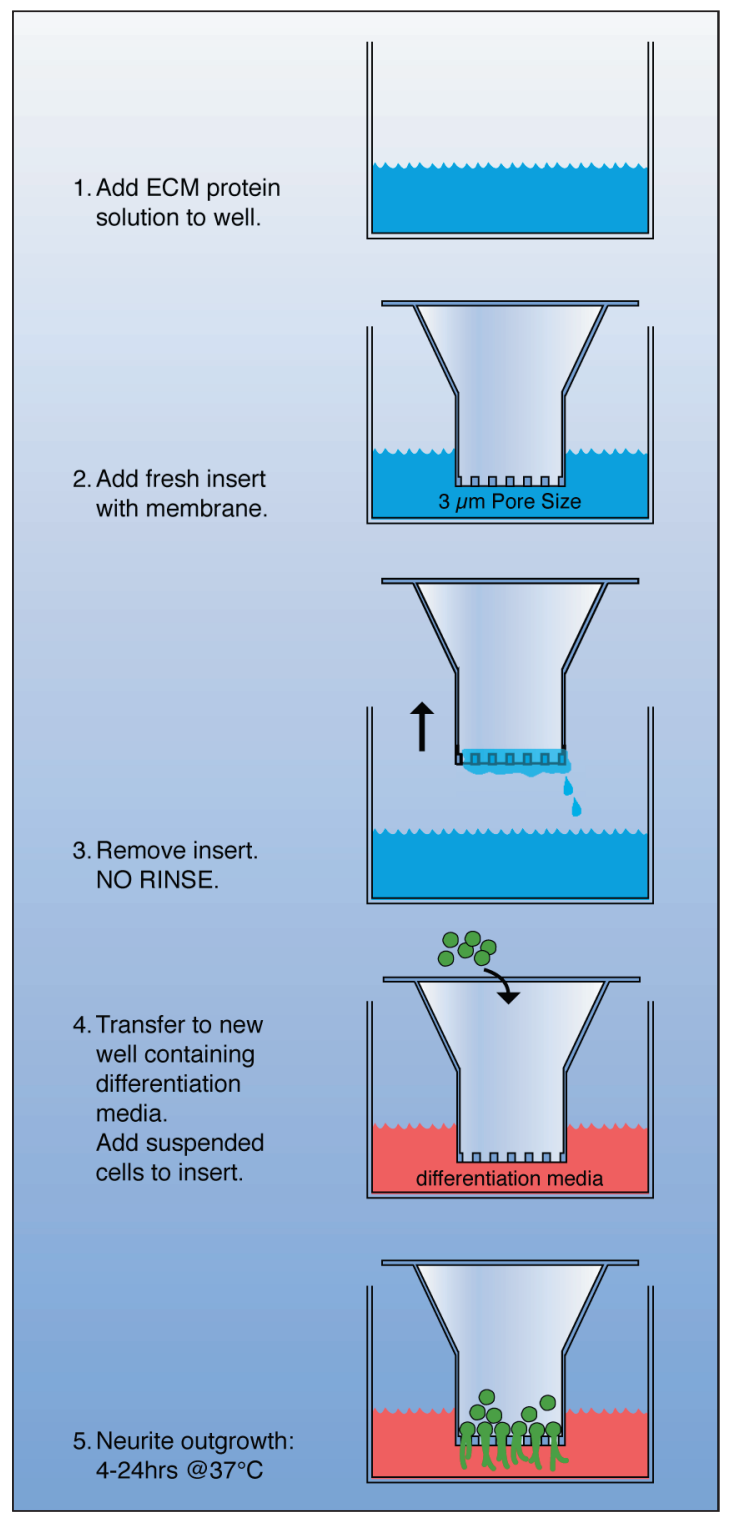

Figure 1. Details of neurite outgrowth chamber technology. Assays were performed in 24-well dishes. Fresh transwell cell culture inserts were placed in wells containing extracellular matrix $(\mathrm{ECM})$ protein solutions and incubated for $2 \mathrm{~h}$ at $37^{\circ} \mathrm{C}$ (steps 1 and 2). The insert was then removed and transferred to a new well containing differentiation media, and suspended cells were added on top of the membrane for a 4- to 24-h incubation at $37^{\circ} \mathrm{C}$ (steps $\left.3-5\right)$.

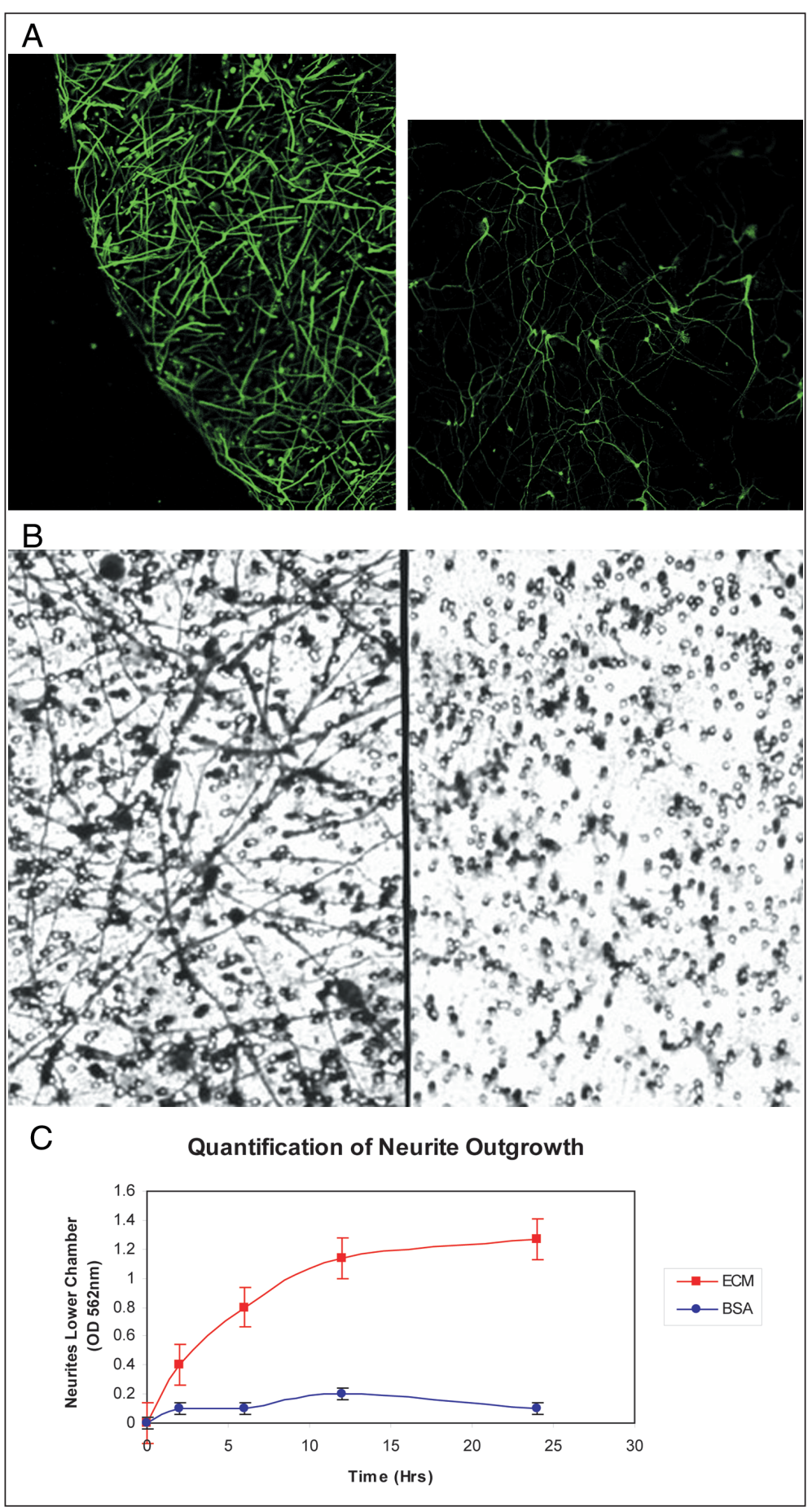

Figure 2. Neurite outgrowth visualization and quantification. (A) Left panel: N1E-115 cells were seeded on a membrane treated with $10 \mu \mathrm{g} / \mathrm{mL}$ laminin/phosphate-buffered saline (PBS). Neurites extended through membrane pores were visualized using a fluorescently labeled anti- $\beta$ IIItubulin. Right panel: PC12 cells, cultured on membranes coated with $10 \mu \mathrm{g} / \mathrm{mL}$ collagen I, revealed neurite outgrowth upon staining with fluorescent-labeled anti-ßIIItubulin. (B) Left panel: neurites from N1E-115 cells extend through $3-\mu \mathrm{m}$ pores of membrane coated with $10 \mu \mathrm{g} / \mathrm{mL}$ laminin/PBS and stained with $0.09 \%$ crystal violet. Right panel: N1E-115 cells, stained with crystal violet, revealed no neurite extensions through pores of membrane coated with $0.2 \%$ bovine serum albumin (BSA)/PBS. (C) Quantification of neurite outgrowth by absorbance $\left(\mathrm{A}_{562}\right)$ readings of crystal violet extracted from stained, isolated neurites. N1E-115 neurite extension was measured over time for laminin-coated (red) or BSA-coated (blue) membranes. The absorbance at each time point is expressed as $\overline{\mathrm{x}} \pm \mathrm{SD}$, calculated for three independent experiments. 
rite extensions were visualized with a microscope focused on the underside of the membrane (Figure 2B). Alternatively, neurites can be stained with a neuronal-specific, fluorescent-labeled antibody, such as $\beta$ IIItubulin (1:100; Chemicon International) (Figure 2A). For quantification of neurite extension, the dye was extracted from crystal violet-stained neurites. First, the cell bodies and neurites were separated from each other to quantify neurites only. Cell bodies were removed from the top chamber (on top of membrane) using a cotton swab (note that all cells and debris should be removed from the top, especially around edges of membrane where it attaches to plastic chamber). A 100 - to $200-\mu \mathrm{L}$ drop of extraction buffer $(25 \% 0.2 \mathrm{M}$ acetate buffer, $\mathrm{pH}$ $4.5,50 \%$ reagent alcohol) was placed on a flat piece of Parafilm ${ }^{\circledR}$. The underside of membrane, containing stained neurites, was placed on top of the drop of extraction buffer so that it covered the entire membrane surface. After a 5min incubation at room temperature, the 100 - to $200-\mu \mathrm{L}$ drop of extraction buffer (containing extracted crystal violet solution) was dispensed into a well of a 96-well plate and quantified at 562 $\mathrm{nm}$ on a spectrophotometer (Figure 2C).

BSA-coated $(0.2 \%)$ membranes were used as negative controls for neurite outgrowth of N1E-115 and PC12 cells. These controls were performed concurrently with assays done using ECMcoated membranes.

According to our results, N1E-115 and PC12 cells extended neurites on laminin- and collagen I-coated membranes, respectively, and could be visualized with either a fluorescently labeled neuronal antibody (Figure $2 \mathrm{~A}$ ) or crystal violet stain (Figure 2B). Crystal violet stain did not reveal any neurite outgrowth when cells were cultured on a BSA-coated membrane (Figure 2B, right panel). Figure $2 \mathrm{C}$ reveals quantification of neurite outgrowth from N1E115 cells, cultured on laminin and BSA-coated membranes, over a 24-h period. Neurite outgrowth at each time point was quantified at $562 \mathrm{~nm}$ following extraction of crystal violet stain from neurites.

In conclusion, the assay presented here is a simple and efficient method for the quantification of neurite outgrowth in a 24-well format. This system will also be applicable for the simultaneous screening of numerous biological and pharmacological agents, the direct evaluation of adhesion and guidance receptor functions responsible for neurite extension and repulsion, and the analysis of gene function in transfected cells.

\section{REFERENCES}

1.Qui, J., D. Cai, and M.T. Filbin. 2000. Glial inhibition of nerve regeneration in mature mammalian CNS. Glia 29:166-174.

2.Fournier, A.E. and S.M. Strittmatter. 2001 Repulsive factors and axon regeneration in the CNS. Curr. Opin. Neurobiol. 11:89-94.

3.Filbin, M.T. 2000. Axon regeneration: vaccinating against spinal cord injury. Curr. Biol. 10:R100-R103.

4.McKerracher, L. 2001. Spinal cord repair: strategies to promote axon regeneration. Neurobiol. Dis. 8:11-18.

5.Schmid, R.S., W.M. Pruitt, and P.F. Maness. 2000. A MAP kinase-signaling pathway mediates neurite outgrowth on L1 and requires Src-dependent endocytosis. J. Neurosci. 20:4177-4188.

6.Ronn, L.C., I. Ralets, B.P. Hartz, M. Bech, A. Berezin, V. Berezin, A. Moller, and E. Bock. 2000. A simple procedure for quantification of neurite outgrowth based on stereological principles. J. Neurosci. Methods
100:25-32

7.Boyden, S. 1963. Cellular recognition of foreign matter. Int. Rev. Exp. Pathol. 2:311-357.

8.Letourneau, P.C. 1975. Cell-to-substratum adhesion and guidance of axonal elongation. Dev. Biol. 44:92-101.

9.Gunderson, R.W. and J.N. Barrett. 1984. Neurite growth cone-substratum adherence increases in vitro. Brain Res. 314:21-26.

10.Lander, A.D., D.K. Fujii, and L.F. Reichardt. 1985. Purification of a factor that promotes neurite outgrowth: isolation of laminin and associated molecules. J. Cell Biol. 101:898-913.

11.Lander, A.D., D.K. Fujii, and L.F. Reichardt. 1985. Laminin is associated with the "neurite outgrowth-promoting factors" found in conditioned media. Proc. Natl. Acad. Sci. USA 82:2183-2187.

12.Turner, D.C., L.A. Flier, and S. Carbonetto. 1989. Identification of a cell-surface protein involved in PC12 cell-substratum adhesion and neurite outgrowth on laminin and collagen. J. Neurosci. 9:3287-3296.

Received 10 March 2003; accepted 29 April 2003.

Address correspondence to Richard Klemke, Innovative Cell Systems LLC, 28835 Single Oak Drive, Suite 110, Temecula, CA 92590, USA.e-mail:rklemke@innovativecell.com

\title{
Catechol dioxygenase is an insensitive reporter for transcription in Mycobacterium smegmatis
}

\author{
Shyam Unniraman ${ }^{1}$ and Valakunja Nagaraja ${ }^{1,2}$ \\ 'Indian Institute of Science and '2Jawaharlal Nehru Centre for Advanced Scientific \\ Research, Bangalore, India
}

BioTechniques 35:256-262 (August 2003)

The whole genome sequencing initiative has provided a wealth of information about mycobacteria $(1,2)$. However, inadequate genetic reagents continue to hinder rapid progress in the field. For instance, the analysis of gene expression in mycobacteria is acutely limited by the lack of sensitive and robust reporter systems. Over the years, there have been isolated reports of the use of a few reporter systems (3-7). However, because of the limited use of individual reporter systems, there is no comparison of the pros and cons of these systems specifically in mycobacteria, unlike in other model organisms such as Escherichia coli. Recently, the systems based on chloramphenicol acetyl transferase (CAT) (8-13) and catechol dioxygenase (CDO, xylE) (6,14-16) have become increasingly popular. The cat reporter gene has been used in many different systems and is well documented to be highly sensitive with an exceptionally large range of linearity. On the negative side, as with 